\title{
COVID-19 PANDEMIC AND IMPENDING GLOBAL MENTAL HEALTH IMPLICATIONS
}

\author{
Kanwar Hamza Shuja ${ }^{1}$, Muhammad Aqeel ${ }^{2}$, Abbas Jaffar ${ }^{3}$ \& Ammar Ahmed ${ }^{1}$ \\ ${ }^{1}$ Quaid-i-Azam University, Islamabad, Pakistan \\ ${ }^{2}$ Foundation University Islamabad, Rawalpindi Campus, Islamabad, Pakistan \\ ${ }^{3}$ Shanghai Jiao Tong University, Shanghai, China
}

received: 30.3 .2020 ;

revised: 3.4.2020;

accepted: 8.4 .2020

\section{SUMMARY}

The increase in organisms transference and infectious pandemics across the globe have been accelerated by an increase in travel, international exchange and global changes in earth's climate. COVID-19, a virus caused by the novel coronavirus that was initially identified on December 2019, in Wuhan city of China is currently affecting 146 territories, states and countries raising distress, panic and increasing anxiety in individuals exposed to the (actual or supposed) peril of the virus across the globe. Fundamentally, these concerns ascend with all infections, including those of flu and other agents, and the same worldwide safeguards are compulsory and suggested for protection and the prevention of further diffusion. However, media has underlined COVID-19 as rather an exclusive threat, which has added to panic and stress in masses which can lead to several mental health issues like anxiety, obsessive compulsive disorder and post-traumatic stress disorder which should be contained immediately in its initial phases.

Key words: COVID-19 - mental health - global distress - novel corona virus

$* * * * *$

\section{INTRODUCTION}

In the wake of 2020, COVID-19 a distinctive strain of coronavirus causing acute respiratory syndrome, appeared in Wuhan city of China and precipitously extended across the globe (Ahmed et al. 2020, Wang et al. 2020). Its case fatality rate is $2.3 \%$ greater than that of influenza and in contrast to severe acute respiratory syndrome (SARS) it is more contagious (Bouey 2020, Yang et al. 2020). Up till March $16^{\text {th }}, 2020$, territories, states and countries outside of China reporting infections to world health organization (WHO), were 146, with an estimated 164837 active cases and a staggering death toll of 6470 globally (WHO 2020). The last time world encountered a similar global pandemic was the influenza outbreak (H1N1), of 1918-19 having an estimates deaths ratios between 50 and 100 million (Johnson \& Mueller 2002), with several reported cases of mental health issues in its aftermath (Young 2016).

Currently with no appropriate cure several of the countries are responding to COVID-19, through a combination of confinement and mitigation strategies (Anderson et al. 2020, Parodi \& Liu 2020). with the objective of deferring major flow of patients and steamrolling the demands of hospital admissions while safeguarding the most vulnerable from infection like the elderly and patients with comorbidities (Bedford 2020). However this method has disrupting the psychosocial life of general public thus creating an impending sense of fear and provoking anxiety and similar mental issues and while many developed countries having the resources to deal with financial and social crises are still finding it difficult to deal with these issues. Third world countries like Pakistan which have a larger portion of population consisting of labours and people with low wages are facing the full brunt of the outbreak with complete close down of various cities within the country leading to frustration, anger, depression and several other psychological disorders (Ahmad et al. 2020).

\section{PANDEMIC AND MENTAL HEALTH}

Several researches have indicated a direct link between chronic diseases such as human immunodeficiency virus (HIV), and tuberculosis with mental disorders like depression (Gale et al. 2018, Mason \& Lyons 2003), in general population (Kuan et al. 2019, van den Heuvel et al. 2013). In similar way studies conducted during and after epidemics such as SARS of 2003 and Ebola of 2014, observed that there was a widespread fear induced overreactive behaviour among the general public (Shultz et al. 2016, Person et al. 2004). In addition to this several psychiatric disorders like anxiety, depression and post-traumatic stress disorder were found particularly in survivors and healthcare workers (Blakey et al. 2019, Gardner \& Moallef 2015, Mak et al. 2009).

Although as of yet the effects of COVID-19 on mental health have not been studied systematically, it is expected to have significant effects based on recent public reaction (Li 2020, Xiang et al. 2020). On basis of this reaction and previous experiences on January, $26^{\text {th }}$, 2020, National Health Commission of China took major steps and issued a notification stipulating guidelines for emergency psychosocial disaster interventions to reduce psychosocial outcomes of COVID-19 outbreak with psychological teams consisting of psychiatrists, mental health professionals and psychological support hotlines (National Health Commission of China 2020). 
Subsequent to which WHO's department of Mental Health and Substance Use on March $18^{\text {th }}, 2020$, developed outline addressing considerations for general and various targeted populations to support for mental health and psychosocial wellbeing (World Health Organization 2020), placing psychiatrists and mental health professionals to help both patients and general public in understanding the possible effect of COVID-19 and assisting their patients, families and public in dealing with the newest threat in most effective ways.

\section{STIGMATIZATION}

As highlighted by WHO in their mental health outline stigmatization and scapegoating of affected persons, health care professionals and authority figures is very common occurrence during epidemics (Rubin \& Wessely 2020, Shigemura et al. 2020) and unfortunately this trend still prevails during current outbreak of COVID-19, as several people of Asian lineage, explicitly Chinesse are victimized by xenophobia and social stigmatization, with immense levels of threats online and during public interactions (World Health Organization 2020). With such reaction from educated and civilized countries, nations like Pakistan where most of the population is still illiterate this stigmatization specifically towards the affected individuals and their families is on rise. Therefore it is essential for the mental health professionals including psychiatrists and psychologists to act as unbiased voice of reasoning and assist in educating the general masses to reduce their fear and stigmatization towards the affected individuals and Chinesse communities.

\section{MEDICAL MISTRUST AND CONSPIRACY THEORIES}

With still no success in creating a working vaccine for COVID-19, there is a general sense of medical mistrust in the masses which is resulting in less use of health care facilities and health condition management (Burkle Jr n.d, Ho 2020). Additionally this mistrust of health facilities has also been linked to variety of diseases and disorders involving autism, cancer and HIV and disparities based on ethnicity and race (Pellowski et al. 2013, Good et al. 2005). Another important aspect that often appears along side medical mistrust during pandemic is of conspiracy theories (Quinn 2018). Studies have pointed several instances where participants held a false belief relating to medical health. This can easily leads and enforces movements such as antivaccination trends during measles outbreak (Jolley \& Douglas 2014) which in turn enforces stigmatization and less adherence to health recommendations.

One prime example can by of Pakistan where still many of the citizens have a general mistrust towards using medicines and prefer herbal or home remedy while simultaneously avoid mental health professionals due to lack of knowledge, believes in myths and fear of being stigmatized (Keynejad 2008). Similarly as seen in many previous cases such as that of polio and the conspiracy theories which many Pakistani had led to rejection of polio vaccinations (Andrade \& Hussain 2018). For this reason media along with officials should come forth and educate people about the importance and existence of not only physical health issues but mental health issues during a pandemic along with medical and mental health professionals to sustain a scientific and fact based presentation and suggestions while addressing the importance of COVID-19 control practices.

\section{ANXIETY AND OBSESSIVE COMPULSIVE DISORDER}

Any uncertain situation can lead to panic induced behavior and with the influence of COVID-19, selfconfinement and an absence of proper treatment for the infectious disease has led masses in panic and anxiety inciting situation (Lunn et al. 2020). Though these anxiety symptoms may not accelerate to diagnostic threshold of DSM-5, still reassurance from mental health professionals can help the individuals to cope with their current anxieties. Likewise contamination obsession which is persistent, unwanted discomfort regarding one's cleanliness and in constant need of washing or sterilizing is usually classified under obessessive compulsive disorder (Williams et al. 2013). And in case of pandemic brought on by an infectious virus this form of OCD can enhances panic resulting in disruption and operative impairment of individual. This should be carefully checked upon as countries like Pakistan not all the people are registered to mental health professionals and can suffer indefinitely in such circumstances. Mental health professionals and clinical psychologists should be attentive towards such impending issues and try to resolve it with utmost care.

\section{AGGRESSION, FRUSTRATION AND POST-TRAUMATIC STRESS DISORDER}

Initially public emotional response to any pandemic is of extreme fear and uncertainty which usually drives towards negative societal behaviors and can involve public mental health concerns like anxiety, insomnia, depression aggression, frustration and hysteria (Shigemura et al. 2020). If compared to previous studies relating to outbreak of SARS, pateints with definite or alleged COVID-19, and are in quarantine will most likely suffer from loneliness, anger and frustration (Xiang 2020). Similarly another concern is for survivors and mental health care professionals to suffer from PTSD. In a study conducted in a hospital in Beijing, quarantined health workers who worked in high risk clinical sites such as SARS unit or had a family member or peer infected by SARS reported significantly higher level of post-traumatic stress symptoms in comparisons 
to those without similar experiences (Kaiser 2020, Yi et al. 2020, Wu 2009). Likewise medical professionals who dealt with SARS patients or worked during outbreak of SARS also stated fear, anxiety, depression and frustration ( $\mathrm{Wu}$ et al. 2009, Liu et al. 2003). In a nation like Pakistan where uncertainty is not only that of COVID-19 but also for many about their next meal and disrupted work life due to lock down emotional disturbances such as aggression and frustration will be common. Comparably those health professionals working in quarantine COVID-19 units with lack of proper protective measures and death of fellow doctors can lead to significant symptoms of post-traumatic stress disorder and mental health professionals should apply therapies such as stress-adaptation model to reduce the level of high stress in health professionals (Folkman \& Greer 2000).

\section{CONCLUSION}

Though the pandemic of COVID-19 has spread fear on not only individual but societal levels and the need to implement proper mental health precautions along with physical health precautions, especially in countries like Pakistan where resources are limited and timely detection and eradication of mental health issues can help the patients in long term sufferings. Other strategies such as online psychological helplines from home can also give an easy access to psychologists and the masses for communication and assistance.

\section{Acknowledgements: None.}

Conflict of interest: None to declare.

\section{Contribution of individual authors:}

Kanwar Hamza Shuja \& Muhammad Aqeel: study design, literature search, first draft, manuscript revisions, approval of the final version.

Abbas Jaffar: literature search, manuscript revisions.

Ammar Ahmed: literature search, manuscript revisions.

\section{References}

1. Ahmad T, Khan M, Khan FM \& Hui J: Are we ready for the new fatal Coronavirus: scenario of Pakistan? Human Vaccines \& Immunotherapeutics 2020; 1-3

2. Ahmed SF, Quadeer AA \& McKay MR: Preliminary identification of potential vaccine targets for the COVID19 coronavirus (SARS-CoV-2) based on SARS-CoV immunological studies. Viruses 2020; 12:254

3. Anderson RM, Heesterbeek H, Klinkenberg $D$ \& Hollingsworth TD: How will country-based mitigation measures influence the course of the COVID-19 epidemic? The Lancet 2020; 395:931-934

4. Andrade GE \& Hussain A: Polio in Pakistan: Political, Sociological, and Epidemiological Factors. Cureus 2018; 10
5. Bedford J, Enria D, Giesecke J, Heymann DL, Ihekweazu $C$, Kobinger $G$ \& Ungchusak K: COVID-19: towards controlling of a pandemic. The Lancet, 2020

6. Blakey SM, Kirby AC, McClure KE, Elbogen EB, Beckham JC, Watkins LL \& Clapp JD: Posttraumatic safety behaviors: Characteristics and associations with symptom severity in two samples. Traumatology, 2019

7. Bouey J: From SARS to 2019-Coronavirus (nCoV): USChina Collaborations on Pandemic Response, 2020

8. Burkle Jr, FM: Declining Public Health Protections within Autocratic Regimes: Impact on Global Public Health Security, Infectious Disease Outbreaks, Epidemics, and Pandemics (n.d.)

9. Folkman $S \&$ Greer S: Promoting psychological wellbeing in the face of serious illness: when theory, research and practice inform each other. Psycho-Oncology: Journal of the Psychological, Social and Behavioral Dimensions of Cancer 2000; 9:11-19

10. Gale SD, Berrett AN, Erickson LD, Brown BL \& Hedges $D W$ : Association between virus exposure and depression in US adults. Psychiatry research 2018; 261:73-79

11. Gardner PJ \& Moallef P: Psychological impact on SARS survivors: Critical review of the English language literature. Canadian Psychology/Psychologie canadienne 2015; 56:123

12. Good MD, James C, Good BJ \& Becker AE: The culture of medicine and racial, ethnic, and class disparities in healthcare. The Blackwell Companion to Social Inequalities. Malden, MA: Blackwell Publishing, Ltd, 2005; 396-423

13. Ho CS: Mental Health Strategies to Combat the Psychological Impact of COVID-19 Beyond Paranoia and Panic, 2020

14. Johnson NP \& Mueller J: Updating the accounts: global mortality of the 1918-1920 "Spanish" influenza pandemic. Bulletin of the History of Medicine 2002; 105-115

15. Jolley D \& Douglas KM: The effects of anti-vaccine conspiracy theories on vaccination intentions. PloS one 2014; 9

16. Kaiser F: Framing risk, reducing panic during virus outbreak. 2020. Retrieved from:

https://asiatimes.com/2020/02/framing-risk-reducingpanic-during-virus-outbreak/

17. Keynejad R: Barriers to seeking help. What stops ethnic minority groups in Redbridge accessing mental health services, 2008

18. Kuan V, Denaxas S, Gonzalez-Izquierdo A, Direk $K$, Bhatti $O$, Husain $S$ \& Lumbers RT: A chronological map of 308 physical and mental health conditions from 4 million individuals in the English National Health Service. The Lancet Digital Health 2019; 1:e63-e77

19. Li W, Yang Y, Liu ZH, Zhao YJ, Zhang Q, Zhang L \& Xiang YT: Progression of Mental Health Services during the COVID-19 Outbreak in China. Int J Biol Sci 2020; 16:1732-1738

20. Liu TB, Chen $X Y$ \& Miao GD: Recommendations on diagnostic criteria and prevention of SARS-related mental disorders. J Clin Psychol Med 2003; 13:188-191

21. Lunn P, Belton C, Lavin C, McGowan F, Timmons $S \&$ Robertson D: Using behavioural science to help fight the coronavirus (No. WP656), 2020

22. Mak IWC, Chu CM, Pan PC, Yiu MGC \& Chan VL: Longterm psychiatric morbidities among SARS survivors. General hospital psychiatry 2009; 31:318-326

23. Mason BW \& Lyons RA: Acute psychological effects of suspected bioterrorism. Journal of Epidemiology \& Community Health 2003; 57:353-354 
24. National Health Commission of China: Principles of the emergency psychological crisis interventions for the new coronavirus pneumonia. 2020. Retrieved from: http://www.nhc.gov.cn/jkj/s3577/202001/6adc08b9665942 $53 b 2 b 791 b e 5 c 3 b 9467$

25. Parodi SM \& Liu VX: From Containment to Mitigation of COVID-19 in the US. JAMA 2020

26. Pellowski JA, Kalichman SC, Matthews KA \& Adler N: A pandemic of the poor: social disadvantage and the US HIV epidemic. American Psychologist 2013; 68:197

27. Person B, Sy F, Holton K, Govert B \& Liang A: Fear and stigma: the epidemic within the SARS outbreak. Emerging Infectious Diseases 2004; 10:358

28. Quinn KG, Kelly JA, DiFranceisco WJ, Tarima SS, Petroll $A E$, Sanders $C \&$ Amirkhanian YA: The health and sociocultural correlates of AIDS genocidal beliefs and medical mistrust among African American MSM. AIDS and Behavior 2018; 22:1814-1825

29. Rubin GJ \& Wessely S: The psychological effects of quarantining a city. BMJ 2020; 368

30. Shigemura J, Ursano RJ, Morganstein JC, Kurosawa M \& Benedek DM: Public responses to the novel 2019 coronavirus (2019-nCoV) in Japan: mental health consequences and target populations. Psychiatry and Clinical Neurosciences, 2020

31. Shultz, JM, Cooper JL, Baingana F, Oquendo MA, Espinel $Z$, Althouse BM \& Mazurik L: The role of fear-related behaviors in the 2013-2016 West Africa Ebola virus disease outbreak. Current psychiatry reports 2016; 18:104

32. van den Heuvel L, Chishinga N, Kinyanda E, Weiss H, Patel V, Ayles $H \&$ Seedat $S$ : Frequency and correlates of anxiety and mood disorders among TB-and HIV-infected Zambians. AIDS care 2013; 25:1527-1535

33. Varnum P: Managing mental health during coronavirus: Experts around the world share insights, 2020. Retrieved from: https://www.weforum.org/agenda/2020/03/covid19coronavirus-mental-health-expert-insights/

34. Wang $Y$, Wang $Y$, Chen $Y \&$ Qin $Q$ : Unique epidemiological and clinical features of the emerging 2019 novel coronavirus pneumonia (COVID $\square 19$ ) implicate special control measures. Journal of Medical Virology, 2020

35. Williams MT, Mugno B, Franklin M \& Faber S: Symptom dimensions in obsessive-compulsive disorder: phenomenology and treatment outcomes with exposure and ritual prevention. Psychopathology 2013; 46:365-376

36. World Health Organization: Coronavirus disease (COVID2019) situation reports. 2020. Available on: https://www. WHO.Int/docs/default-source/coronaviruse/situationreports/20200221-sitrep-32-covid-19

37. World Health Organization: Mental health and psychosocial considerations during the COVID-19 outbreak, 18 March 2020 (No. WHO/2019-nCoV/MentalHealth/2020.1)

38. Wu P, Fang Y, Guan Z, Fan B, Kong J, Yao Z \& Hoven $C W$ : The psychological impact of the SARS epidemic on hospital employees in China: exposure, risk perception, and altruistic acceptance of risk. The Canadian Journal of Psychiatry 2009; 54:302-311

39. Xiang YT, Yang Y, Li W, Zhang L, Zhang $Q$, Cheung $T$ \& $\mathrm{Ng} \mathrm{CH}$ : Timely mental health care for the 2019 novel coronavirus outbreak is urgently needed. The Lancet Psychiatry 2020; 7:228-229

40. Yang $Y$, Peng $F$, Wang $R$, Guan K, Jiang $T, X u G$ \& Chang C: The deadly coronaviruses: The 2003 SARS pandemic and the 2020 novel coronavirus epidemic in China. Journal of Autoimmunity 2020; 102434

41. Yi Y, Lagniton PN, Ye S, Li E, Xu RH, Zhong BL \& Li WT: COVID-19: what has been learned and to be learned about the novel coronavirus disease. Int J Biol Sci 2020; 16:1753-1766

42. Young JM: The Politics of Contagion, 2016

Correspondence:

Kanwar Hamza Shuja, MPhil Research Scholar

Quaid-i-Azam University

Islamabad, Pakistan

E-mail:kanwarmphil18@nip.edu.pk 